\begin{tabular}{|c|c|c|c|c|c|c|}
\hline \multirow{4}{*}{ Impact Factor: } & ISRA (India) & $=4.971$ & SIS (USA) & $=0.912$ & ICV (Poland) & $=6.630$ \\
\hline & ISI (Dubai, UAE & $=0.829$ & РИНЦ (Russia) & $=0.126$ & PIF (India) & $=1.940$ \\
\hline & GIF (Australia) & $=0.564$ & ESJI (KZ) & $=8.716$ & IBI (India) & $=4.260$ \\
\hline & JIF & $=1.500$ & SJIF (Morocco) & $=5.667$ & OAJI (USA) & $=0.350$ \\
\hline
\end{tabular}

\section{SOI: 1.1/TAS DOI: $10.15863 /$ TAS \\ International Scientific Journal Theoretical \& Applied Science}

p-ISSN: 2308-4944 (print) e-ISSN: 2409-0085 (online)

Year: $2020 \quad$ Issue: 03 Volume: 83

Published: $30.03 .2020 \quad$ http://T-Science.org
QR - Issue

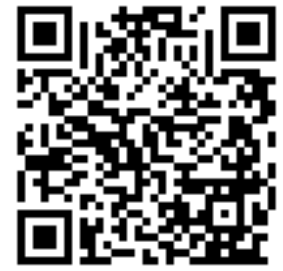

QR - Article

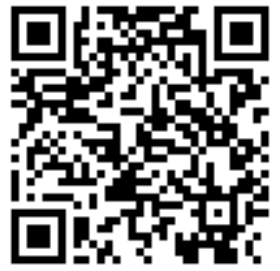

Mashkhura Khafizova

Samarkand state Institute of architecture and construction Russian language teacher, Uzbekistan

\title{
THEORETICAL BASES OF FORMATION OF MOTIVATION IN TEACHING SPEECH SKILLS AT THE MODERN STAGE
}

Abstract: This article discusses the formation of motivation among students in teaching their speech skills. There are studied some teaching methods applied to heighten the interest of students in acquiring speech skills effectively in the process of learning languages. The individual characteristics of students, the presence of various types of motivation and factors affecting their improvement in the learning process are analyzed.

Key words: motivation, motivated student, productivity, purposefulness, integrative motivation, instrumental motivation, motivational component.

Language: Russian

Citation: Khafizova, M. (2020). Theoretical bases of formation of motivation in teaching speech skills at the modern stage. ISJ Theoretical \& Applied Science, 03 (83), 125-128.

Soi: http://s-o-i.org/1.1/TAS-03-83-27 Doi: crossef https://dx.doi.org/10.15863/TAS.2020.03.83.27

Scopus ASCC: 3304.

\section{ТЕОРЕТИЧЕСКИЕ ОСНОВЫ ФОРМИРОВАНИЯ МОТИВАЦИИ ПРИ ОБУЧЕНИИ РЕЧЕВЫМ УМЕНИЯМ НА СОВРЕМЕННОМ ЭТАПЕ}

Аннотация: В данной статье рассматриваются вопросы формирования мотивации у учашихся при обучении их речевым умениям. Изучаются педагогические методы для пробуждения интереса у обучаюшихся эффективно усвоить речевые навыки в прочессе изучения языков. Анализируются индивидуальные особенности учащихся, наличие у них различных видов мотивации и факторы, влияющие на их повышение в процессе обучения.

Ключевые слова: мотивация, мотивированный учащчийся, продуктивность, целенаправленность, интегративная мотивация, инструментальная мотивация, мотивационный компонент.

\section{Введение}

Одной из центральных проблем для изучения и исследования в методике преподавания языка, особенно иностранного языка в качестве второго, является речевое умение, более конкретно, обучение речевым умениям. Речевые умения определяют способность учащегося изложить определённую мысль, идею, предложение на том или ином языке, с помощью чего может быть осуществлён информационный процесс, то есть обмен имеющимися сведениями учащимися между собой и между учащимися и преподавателем. Безусловно, основная часть знаний и навыков говорящего может быть определена на основе его умений строения письменной и устной речи и её эффективной передачи, что представляет собой наличие отдельной значимости исследования в современной педагогике. На основе реализации продуктивного обучения речевым умениям лежит побуждение у учащихся желания приобрести необходимые для этого навыки и стремления применять их в процессе практической деятельности, то есть, это формирование того, чего мы в настоящее время называем мотивацией. Именно, мотивация, которая создаётся в учебной аудитории при обучении речевым умениям способствует как к выявлению отдельных интересов у учащихся, так и их формированию и поэтапному развитию.

Возникает некая трудность при передаче отдельного определения к самому понятию 


\begin{tabular}{|c|c|c|c|c|c|c|}
\hline \multirow{4}{*}{ Impact Factor: } & ISRA (India) & $=4.971$ & SIS (USA) & $=0.912$ & ICV (Poland) & $=6.630$ \\
\hline & ISI (Dubai, UAE & $=0.829$ & РИНЦ (Russia & $=0.126$ & PIF (India) & $=1.940$ \\
\hline & GIF (Australia) & $=0.564$ & ESJI (KZ) & $=8.716$ & IBI (India) & $=4.260$ \\
\hline & JIF & $=1.500$ & SJIF (Morocec & $=5.667$ & OAJI (USA) & $=0.350$ \\
\hline
\end{tabular}

мотивация; легче рассмотреть этот термин в рамках понятия мотивированный учащцийся, что заключает в себе того, кто страстно желает и стремится приложить все свои усилия в учебный процесс и дальнейший прогресс. При наличии мотивации у обучающихся и преподавательская, и учебная деятельность становится не только менее затруднительной, но и более продуктивной. Действительно, мотивация имеет большее значение для достижения ожидаемых результатов в процессе овладения речевыми умениями по сравнению с естественной способностью учащегося к языковым навыкам, то есть, успех может быть достигнут независимо от того, какая способность у отдельного студента, ибо стремления и усилия мотивированного студента зачастую могут превышать те, которыми обладает более способный студент.

Главная ответственность преподавателя заключается не только в предоставлении возможностей учащимся и обеспечении необходимых условий для их образовательной деятельности, но и в “подталкивании” студентов осознать собственный потенциал и сделать максимальный прогресс, что и может быть эффективно реализовано путём укрепления мотивации у обучающихся. Если рассмотреть обучение речевым умениям в рамках изучения определённого языка, то стоит отметить, что на различных исследованиях было обнаружено, что мотивация очень тесно связана с достижением успеха в изучении языка. [3, 74] Однако, здесь возникает вопрос: что является причиной, а что результатом? Другими словами, успех в изучении языка способствует появлению мотивации или мотивация приводит к успеху? Другой вопрос, который требует конкретного научного доказательства, касается того, является ли мотивация более или менее важным чем естественная индивидуальная способность к изучению языков. В данном случае, чтобы найти ответ на вышеуказанный вопрос, преподавателю необходимо разработать такие методы при обучении речевым умениям, которые помогут пробудить у студентов желание изучить либо повысить имеющийся интерес к изучению речевых навыков, поскольку продуктивность учебного процесса чаще всего достигается путём создания той атмосферы в учебной аудитории, где обучающиеся мотивированны, чтобы усвоить урок, нежели чувствуют обязанность.

Авторы исследования эффективного изучения языка Н. Нейман, М. Фролих, Г. Стерн и А. Тодеско в своём научном издании "The Good Language Learner" пришли к выводу, что самые успешные ученики не те, которым изучение языка даётся легко, a те, которые проявляют определённые признаки, большей частью, связанные с мотивацией. Некоторые из них можно представить в следующем виде:

- Позитивная ориентированность на задачу. Учащийся охотно настраивается на решение определённых задач и вопросов и бывает уверенным в своём успехе.

- Личная заинтересованность. Учащийся считает важным добиться успеха в учебной деятельности для того, чтобы повысить личную позитивную самооценку.

- Необходимость достижений. Учащийся чувствует необходимость преодолеть трудности и преграды и достичь поставленных целей.

- Большие устремления. Учащийся бывает амбициозным и стремится к высокому профессиональному уровню.

- Целенаправленность. Учащийся осознаёт обучения или определённых учебных занятий и прилагает свои усилия для их изучения.

- Выносливость. Учащийся постоянно прилагает больше усилий в учебную деятельность и не обескураживается неудачами или низким темпом прогресса.

- Терпимость к неопределённости или двусмысленности. Учащийся не обескураживается теми случаями или ситуациями, которые влекут за собой недоразумения или путаницы. [3, 275]

Помимо этого, многие другие индивидуальные особенности обучающихся, такие как самостоятельность, сопереживание, сосредоточенность на самом себе или на внешних предметах, были изучены, однако итоги исследования оказались менее убедительными.

Ф.А. Теучеж в своей работе «Проблемы речевой деятельности обучающихся в процессе формирования коммуникативно-речевых умений» утверждает, что умение обучающихся - это показатель и определяющий критерий их уровня речевого развития. [1] Важно заметить, что для формирования мотивации у студентов при обучении речевым умениям определить наличие разных видов мотивации для разных обучающихся. Р. Гарднер и У. Ламберт в своей работе Attitudes and Motivation in Second Language Learning описали интегративный и инструментальный виды мотивации, [3, 276] подразумевая, что интегративная мотивация проявляется у тех учащихся, которые изучают язык в целях изучения культуры и быта народов, говорящем на этом язык; в то время, как инструментальная мотивация проявляется тогда, когда учащиеся изучают язык, учитывая перспективы для карьерного роста или исходя из других интересов. Также мотивацию можно рассмотреть в виде внутренней - когда язык изучается исходя из собственного желания и внешней - когда различные внешние факторы становятся стимулом для изучения языка. Как 


\begin{tabular}{|c|c|c|c|c|c|c|}
\hline \multirow{4}{*}{ Impact Factor: } & ISRA (India) & $=4.971$ & SIS (USA) & $=0.912$ & ICV (Poland) & $=6.630$ \\
\hline & ISI (Dubai, UAE & $=0.829$ & РИНЦ (Russia & $=0.126$ & PIF (India) & $=1.940$ \\
\hline & GIF (Australia) & $=0.564$ & ESJI (KZ) & $=8.716$ & IBI (India) & $=4.260$ \\
\hline & JIF & $=1.500$ & SJIF (Morocce & $=5.667$ & OAJI (USA) & $=0.350$ \\
\hline
\end{tabular}

внутренний, так и внешний виды мотивации играют важную роль для преподавателя при формировании мотивации в учебной аудитории, особенно, внутренняя мотивация тесно связана с тем, что называют 'когнитивным стимулом', то есть когда появляется желание изучать язык и языковые навыки для собственного совершенствования, что обычно проявляется у детей и, зачастую это желание угасает с возрастом.

При формировании мотивации у учащихся значительна роль и самого преподавателя, его методов, которые он применяет для организации продуктивного занятия, эффективных заданий и повышает интерес у студентов к изучению речевых навыков. Т.А. Трифонова в своей работе «Создание установок в процессе развития речевого умения» говорит о том, что в целях развития речевого умения у обучаемых учителю необходимо использовать установки. [2] Под установкой следует понимать предпосылаемое речевому упражнению письменное или устное высказывание, которое благодаря наличию в нём мотивационного, содержательного, деятельностного и организационного компонентов, способно управлять речевой деятельностью и поведением учащихся в условиях заданной в упражнении ситуации и коммуникативной задачи. Учёная утверждает, что одним из необходимых компонентов установки является мотивационный компонент, основной функцией которого является побуждение учащихся к высказыванию. [2] Обеспечить необходимый уровень коммуникативной мотивации учащихся возможно в том случае, если данный компонент установки ориентирован на учёт личностных свойств учащихся, их мировоззрения, контекста деятельности, личного опыта, а также области желаний, интересов, склонностей, эмоционально-чувственной сферы, статуса учащихся в группе и т.п. Отсутствие мотивационного компонента в установке приводит к формальному выполнению задания учащимися, ибо оно не окрашено личностным смыслом.

Стоит отметить, что в большинстве случаев внешние факторы, такие как поощрение преподавателя, самоудовлетворённость, одобрение со стороны других, достижение более высокого результата по сравнению с другими, способствуют повышению мотивации и развития интереса у учащегося, поскольку самостоятельно достигнутый успех в решении определённой задачи побуждает студента попытаться решить другую задачу, более сложную по сравнению с предыдущей. Однако, мотивация не всегда определяется успехом; она иногда может пробудиться после того, как учащийся сталкивается с неудачей, промахами во время учебной деятельности, ибо успех теряет свою ценность, если с лёгкостью его можно достичь. В данном случае перед преподавателем стоит задача осведомлять учащихся об их ошибках и недостатках, над которыми они могут самостоятельно работать, чтобы развивать имеющиеся навыки и изучать новые.

$$
\text { Учащиеся часто мотивируются }
$$

требовательностью преподавателя, потому что в таком случае они начинают чувствовать ответственность изучать данный материал исходя из того, что это задаётся преподавателем, который будет этого требовать в заданной форме, в заданное время. Однако, не стоит забывать, что требования должны быть в таком виде, которые могут постепенно преобразовать ответственность учащихся в их личное желание усвоить урок, ибо чрезмерная требовательность, как бы парадоксально это не звучало, может привести к обратному результату, когда интерес у обучающихся может со временем угасать.

Тесты и соперничество также являются движущей силой для учащихся: когда студенты заранее знают, что будет тестироваться уровень их знаний после усвоения определённого материала, в них пробуждается интерес к тщательному изучению данного материала. Соперничество среди учащихся, пробуждая дух конкуренции, мотивирует студентов лучше овладеть навыками и умениями в целях опережения своих соперников. Однако, для формирования одинаковой для всех учащихся мотивации преподавателю предстоит создать в аудитории атмосферу здоровой конкуренции, где каждый студент мог бы иметь шанс проявить себя в чём-то лучше других, именно после таких групповых состязаний учащиеся бывают более самоуверенными, менее напряжёнными и одинаково мотивированными.

Таким образом, исследования проблемы теоретических основ формирования мотивации при обучении речевым умениям на современном этапе выявило, что сегодня пробуждение интереса у учащихся требует не ограничиваться лишь определёнными методами преподавания, применением одинаковых способов в целях повышения их мотивации. Действительно, требовательность, строгость или, наоборот, постоянная поддержка преподавателя служит главным стимулом для обучающихся, однако интересно проведённый урок преподавателем служит как познавательной, так и более мотивирующей силой для студентов, ибо действительная мотивация у учащегося пробуждается не только хорошо организованным уроком, но и тем энтузиазмом и желанием учителя, с которым он преподаёт. 


\begin{tabular}{|c|c|c|c|c|c|c|}
\hline \multirow{4}{*}{ Impact Factor: } & ISRA (India) & $=4.971$ & SIS (USA) & $=0.912$ & ICV (Poland) & $=6.630$ \\
\hline & ISI (Dubai, UAE & $=0.829$ & РИНЦ (Russi: & $=0.126$ & PIF (India) & $=1.940$ \\
\hline & GIF (Australia) & $=0.564$ & ESJI (KZ) & $=8.716$ & IBI (India) & $=4.260$ \\
\hline & JIF & $=1.500$ & SJIF (Moroce & $=5.667$ & OAJI (USA) & $=0.350$ \\
\hline
\end{tabular}

\section{References:}

1. Teuchezh, F.A. (2013). Problemy rechevoj dejatel'nosti obuchajushhihsja v processe formirovanija kommunikativno-rechevyh umenij. Izvestija VGPU, №10 (85).

2. Trifonova, T. A. (2008). Sozdanie ustanovok v processe razvitija rechevogo umenija. Obrazovanie i nauka, №7(55).

3. Penny, U. (2003). A course in language teaching: practice and theory. the United Kingdom: The University Press, Cambridge.

4. Gardner, R., \& Lambert, W. (1972). Attitudes and Motivation in Second Language Learning, Rowley, Mass.: Newbury House.

5. Naiman, N., Froelich, M., Stern, H.H., \& Todesco, A. (1978). The Good Language Learner, Research in Education Series, No.7, Toronto: Ontario Institute for Studies in Education.
6. Trifonova, T.A. (2009). Teorija i praktika sozdanija $i$ ispol'zovanija ustanovki kak instrumenta upravlenija processom razvitija rechevogo umenija: dis. ... kand. ped. nauk: 13.00.02. Moscow.

7. Bahtin, M.M. (1979). Problema teksta v lingvistike, filologii $i$ drugih gumanitarnyh naukah. (p.250). Moscow.

8. Car'kova, V.B. (1977). Ustanovka kak faktor organizacii rechevyh uprazhnenij. Izv. Voronezh. gos. ped. in-ta, T. 181, p.105.

9. Orlov, V.I. (1995). Znanija, umenija, navyki obuchenija. Moscow.

10. Urakova, F.K. (2008). Psihologopedagogicheskie osnovy formirovanija kommunikativno-rechevyh umenij uchashhihsja nacional'noj shkoly. Izv. Volgogr. gos. ped. unta, № 6, pp. 44-47. 